\title{
Direito Administrativo
}

\section{ILÍCITO PENAL E SANÇÃO DISCIPLINAR}

\author{
FERNANDO ANDRADE DE OLIVEIRA
}

Docente Livre de Direito Administrativo

Sumário: $O$ pôder sancionador do Direito. Sanções penais e administrativas. A autonomia do Direito disciplinar. Orientação do direito positivo e da doutrina ante o ilícito penal e a infração disciplinar. A necessidade da reformulação das normas de Direito Administrativo, visando atender as peculiariedades do poder disciplinar pela Administração Pública.

1. A ordem jurídica é garantida pela sua própria capacidade de eficazmente reagir contra qualquer ação que lhe seja contrária e através de medidas de autoconservação que constituem as sanções, aplicáveis em sentido repressivo ou mèramente preventivo, conforme sejam opostas a comportamentos que infriniam ou apenas ameacem situações de Direito. A firma Hans Kelsen que um ato jurídico sòmente alcança seu objetivo quando prescreve ou autoriza uma sanção contra os que ao mesmo se oponham, aduzindo que, embora tradicionalmente se defina o fato ilícito com uma interrupção do Direito, é, na verdade, a existência mesma do Direito, a sua validez, que se afirma ante a ilicitude, pela reação do poder sancionador contido no ordenamento jurídico (1).

2. E' pois a sanção, inserida no sistema de Direito, o seu elemento vitalizador. Atuando sob formas diversas, de acôrdo com a natureza da conduta antijurídica, produz a sanção efeitos sôbre o patrimônio ou sôbre a pessoa do autor ou responsável pelo ato ilícito. Temse especialmente mencionado, dentre as sanções, a obrigação de indenizar e a pena (2). Há quem qualifique a pena exclusivamente como medida de repressão, diferenciando-a da detenção policial que, como sanção preventiva, visa impedir a ação ilícita com o obstáculo físico da prisão (3). E' verdade que a pena assume uma característica especial, de índole essencialmente repressiva e particular severidade,

1. Hans Kelsen - Teoria Pura del Derecho - B. Aires, pgs. $87 / 8$.

2. F. Carnelutti - Teoria General del Derecho - Madrid, pgs. 45/6. Luiz Legaz Lacambra Filosofia del Derecho, pgs. 603/5.

3. F. Carnelutti - op. loc. cit. 
quando a ilicitude jurídica toma a forma específica e mais grave do delito penal (4). Mas devemos considerar que até alcançar essa graduação extrema, em que se converte na sanção máxima do Direito, é a pena adotada para coibir ou repelir as mais diferentes manifestações ilícitas e em função das quais opera com rigôr mais ou menos intenso, ora constituindo sanção de caráter econômico, ora sanção corporal, apresentando-se por vêzes com função preventiva, por outras como fôrça repressiva.

3. Atuando em setor próximo aquele em que se impõe a pena criminal, encontra-se uma outra espécie de sanção, de natureza predominantemente preventiva e que se correlaciona com as transgressões ou contravenções administrativas, classificadas sob a denominação genérica de delitos de polícia. Essas penas e as infrações a que correspondem, são estudadas pelo Direito Penal Administrativo e se situam na esfera de incidência do poder de polícia da Administração Pública. O campo em que operam essas penas se tem ampliado na medida em que se desenvolve e aprofunda, no meio social, a intervenção do Estado. Enquanto a função da polícia judiciária está limitada a de orgão auxiliar do Poder Judiciário, na repressão do crime, cabe à polícia administrativa uma larga participação no âmbito da organização social e jurídica. As atribuições da polícia administrativa compreendem, em síntese, tôdas as atividades que possam afetar a ordem pública e a segurança dos indivíduos e seus bens. A ação policial se desenvolve "num plano muito extenso, não sendo possível uma discriminação de todos os casos em que poderá intervir, com o propósito de realizar o objetivo de prevenção de males que afetam o interêsse coletivo". (5). No poder de polícia, exercido sôbre pessoas e coisas, para atender o interêsse público, estão incluídas "todas as restrições impostas pelo poder público aos indivíduos, em benefício do interêsse coletivo, saúde, ordem pública, segurança e, ainda mais, os interêsses econômicos e sociais" (6). Marcelo Caetano nos transmite a definição de polícia dada por Santi Romano: o conjunto de limitações, eventualmente coativas, da atividade dos indivíduos, impostas pela Administração a fim de prevenir os danos sociais que dessa atividade possam resultar. (7).

Dever-se-ia mencionar, também, aquelas sanções de caráter pecuniário, utilizáveis pelo Estado com o objetivo de se assegurar dos meios econômicos necessários à satisfação das necessidades públicas e representadas, especificamente, pela multa fiscal.

4. Mas o que se deseja, precipuamente, através da breve exposição que se fez acêrca do elenco de sanções contidas no ordena-

\footnotetext{
4. Luiz Legaz Lacambra - op. cit., pg. 608. Anibal Bruno - Direito Penal, 2a. ed., val. 1/1.0, pg. 11.

5. Onofre Mendes Júnior - Direito Administrativo, 2a. ed. 1/79.

6. Themistocles Brandão Cavalcanti - Tratado de Direito Administrativo, 4a. ed., vol. III'5.

7. Marcelo Caetano - Manual de Direito Administrativo, 3a. ed., pg. 644.

8. Luiz Jiménez de Asúa - La Ley y el Delito - 2a. ed. pgs. 21/23.
} 
mento jurídico, e das suas finalidades, é bem situar a posição das normas relativas ao Direito Disciplinar, para distinguí-las das que integram o Direito Penal e, mesmo, o chamado Direito Penal Administrativo. Pois o certo é que as infrações e sanções disciplinares, confinadas ao estreito círculo das relações entre o Estado ou o particular, e seus servidores, dotadas que são de peculiariedades próprias, guardam considerável distância dos delitos e penas criminais ou policiais. Mesmo aqueles que entendem ser a antijuridicidade característica geral do delito, tendo por inexistente um injusto penal, outro civil, outro administrativo, desde logo salientam que, embora tendo todos as mesmas origens, separam-se nas consequências e, portanto, nas sanções. E ainda mais: as normas disciplinares aplicáveis por uma sociedade ou corporação aos seus membros, nada têm com o Direito Penal, porque alí a repressão é justificável contra qualquer procedimento que comporte uma concepção vaga e imprecisa de má conduta (9).

5. Reportando-se a obra clássica de Goldschmidt, diz Anibal Bruno que o Direito Penal Administrativo, ou das contravenções, no qual se deve incluir o ilícito de polícia, deve pertencer antes ao Direito Penal que ao Direito Administrativo, mas não se poderá confundir quaisquer desses regimes punitivos com o Direito disciplinar, público ou privádo, que ora compreendendo sanções que a Administração Pública impõe aos seus subordinados, para a ordem e execução regular dos serviços, de acôrdo com os respectivos regulamentos", ora diz respeito "às sanções cominadas em estatutos e regulamentos de corporações, associações e sociedades comerciais, culturais, esportivas, beneficientes, etc., para a disciplina na vida do grupo e a consecução dos seus fins. Tanto o Direito disciplinar público, como o privado conclue Anibal Bruno - distinguem-se do "verdadeiro magistério punitivo que o Estado exerce, em defesa dos bens jurídicos fundamentais para a convivência social, sobre todos os que estão subordinados ao seu império. Só êste deve receber o nome de Direito Penal". (10). Êsse mesmo entendimento é o que também prevalece entre os mais eminentes tratadistas do Direito Administrativo: o Direito disciplinar participa da natureza das atividades a que dedica sua atenção; o Estado não exercita o poder disciplinar como Estado, mas sim como uma modalidade de dominação sôbre os seus funcionários, no recinto das repartições e que é inerente a łodo grupo de convívio humano; essa dominação é a que possue o pai, em relação à família, as associações, quanto aos seus membros. E precisamente por não se tratar de um poder de índole eminentemente estatal é que das penas disciplinares não podem tratar o "habeas corpus" e o mandado de segurança, salvo para apreciar lhes a legalidade (11).

6. O poder disciplinar esgota-se todo na esfera de exercício das atividades dos funcionários ou empregados, a fim de assegurar, em

9. Anibal Bruno - op. cit. pg. 14/15.

10. Anibal Bruno - op. cit. pg. 14/15.

11. Ruy Cirne de Lima - Princípios de Direito Administrativo - pg. 214/6. 
forma preventiva ou repressiva, o cumprimento dos deveres jurídicos da função ou do emprêgo. Porisso o Direito disciplinar sòmente está presente enquanto persiste tais relações - no que também se diferencia do Direito Penal, em sentido estrito. Aos regimes disciplinares são outrossim inaplicáveis os princípios da reserva legal ou penal: nullum crimen sine lege e nulla poena sine lege. $\mathrm{E}^{\prime}$ que embora se exerça em reduzida circunscrição, dispõe o Direito disciplinar de poderes mais dilatados e as suas sanções se impõem mesmo quando inexistam normas especiais, que "configurem a violação dos deveres e a gradação das punições" (12). Além da tipicidade raão ser característica das infrações disciplinares, a imposição das respectivas sanções se realiza sem vinculação a processo rigorosamente jurisdicionalizado ou regulado (13). Como bem assinala Gaston Jèze, a repressão disciplinar não visa castigar o infrator, pela sua maldade, ou por suas intenções de danificar ou violentar as leis sociais de ordem pública e às vêzes atua simplesmente contra atos inoportunos, negligências ou omissões, desde que prejudiciais ao bom funcionamento dos serviços; porisso confundir tais faltas com delitos penais, mesmo quando eventualmente praticados pelo funcionário público, será um erro capital (14). Baband, ao seu tempo, destruiu a tese dos que viam em as normas disciplinares um direito penal especial dos servidores públicos e em que, conforme a gravidade das infrações cometidas, ora a séde administrativa, ora a jurisdicional penal, aplicaria as sanções cabíveis. No Direito penal não há um delito de violação do dever profissional, mas apenas casos exatamente definidos que não comprometem apenas as relações particulares entre o Estado e o funcionário, senão a ordem pública em geral. (15). Porisso é que afirmou Max Ernesto Mayer que o exercício do poder disciplinar é administração e o do poder criminal é justiça. Baseados ainda nas distinções substanciais que separam o ilícito penal da infração de serviço é que também se pronunciam os tratadistas no sentido de que a imposição de pena disciplinar e outra criminal, pelo mesmo fato, não incide na regra jurídica "non bis in idem" (16).

7. O direito positivo vigente no Brasil, ou mais especificamente, a Lei n. ${ }^{\circ} 1.711$, de 28 de outubro de 1952 e que dispõe sôbre o Estatuto dos Funcionários Públicos Civís da União, estabelece que "pelo exercício irregular de suas atribuições, o funcionário responde civil, penal e administrativamente (art. 196), abrangendo a responsabilidade penal "os crimes e contravenções imputadas ao funcionário nessa qualidade" (... art. 198), sendo que a responsabilidade administrativa resultará de "atos ou omissões praticados no desempenho do cargo

12. Benjamin Villegas Basavilbaso - Derecho Administrativo, vol. III/530/31.

13. Marcelo Caetano - op. cit. pg. 498.

14. Gaston Jése - Princípios Generales del Derecho Administrativo - B. Aires, vol. II/92. cit., pg. 551; Amilcar Araujo Falcão - Funcionário Público - Natureza da pena disciplinar - Rev. Dir. Adm. vol. 148/531.

15. Laband - Le Droit Public de L’Empire Allemand, apu Benjamin Villegas Basavilbaso, op. plinar - Rev. Dir. Adm. vol. 48/531.

16. Cf. Paul Duez, Guy Debeyere e Marcel Waline, apud José Cretella Júnior - Direito Ad. 
ou função" (art. 199). Ainda reza o Estatuto que "as cominações civís, penais e disciplinares, poderão acumular-se, sendo uma e outras independentes entre sí, bem assim as instâncias civil, penal e administrativa" (art. 200). Essas disposições legais se harmonizam satisfatòriamente com as mais modernas teorias e pelas quais é francamente reconhecida a autonomia do Direito disciplinar, no tocante à qualificação das infrações e à aplicação das correspondentes sanções.

8. Ocorre, todavia, que pelo art. 207, do referido corpo estatutário, a pena de demissão poderá ser imposta em casos taxativamente enumerados, dentre os quais o de praticar o funcionário (crime contra a administração pública (art. 207, n. I). Essa exigência, combinada com os preceitos dos artigos 226 e 229 da mesma Lei, determinando a remessa do processo de Inquérito administrativo "à autoridade competente", em se tratando de infração" capitulada na lei penal", tem levado alguns autores a concluir que a declarada independência entre as instâncias penal e administrativa é apenas relativa, eis que as decisões, em matéria disciplinar, verificadas as hipóteses consideradas, ficaria vinculada ao juizo criminal. Cogita-se mesmo de um processo administrativo criminal, cuja última fase consistiria na sua remessa à justiça penal, aguardando-se, posteriormente, "o resultado da sentença criminal absolutória ou condenatória para, conforme o caso, reviver ou não o resultado a que se chegou na instância administrativa" (17).

9. Francisco Campos, em extenso e erudito parecer, examina o problema da repercussão, na instância disciplinar, do julgamento proferido pela justiça criminal e que declare a inexistência de fato que constitua ilícito penal e administrativo. A mesma questão desponta quando, em tais condições, é negada pelo juizo penal a autoria proclamada no processo disciplinar. Os princípios que predominam, quanto à matéria, seriam os mesmos que regulam os efeitos da prática de crime na esfera civil (Código Civil, art. 1.525). O que se expõe é que cada jurisdição exerce, em separado, uma parcela do poder jurisdicio. nal do Estado, "fundada em centro comum, onde se origina a autoridade das suas decisões". A separação de jurisdições, consiste em um "processo técnico de diversificação ou repartição de competências" e, desempenhando tôdas a mesma função, embora aplicada a objetos diferentes, há a necessidade do mútuo respeito das suas respectivas atividades, desde que mantidas" nos limites das suas compstências e adstritas ao objeto específico da sua função". Não sendo, pois, impenetráveis as diversas instâncias, mas coexistindo em regime de mútua colaboração - explica Francisco Campos - a regra contida no art. 1.525 do Código Civil resulta do reconhecimento da fôrça absoluta e erga omnes dos julgados criminais e uma vez que o juiz penal, segundo o Tribunal de Conflitos, da França, tem a plenitude da jurisdição. E isso porque, sustenta ainda Francisco Campos, é na justiça criminal

17. José Cretella Júnior - op: cit., pgs. 166/7. 
que se manifesta "de maneira mais direta, mais veemente, mais ostensiva, o princípio de ordem pública". Argui-se finalmente que, com maiores razões, a instância penal deve se impôr sôbre a disciplinar porque esta não reune "os caracteres formais e técnicos que configuram o poder jurisdicional pròpriamente dito; as atividades administrativas se desenvolvem mediante processos apenas assemelhados aos judiciais, desligadas das formalidades e técnicas a que êstes últimos estão rigorosamente subordinados. Assim, constituiria uma falsa questão, "a relativa à força da coisa julgada penal sobre os pretensos, atos jurisdicionais da Administração" (18).

10. Em sua magistral obra sôbre a responsabilidade civil, Aguiar Dias disserta longamente sobre as condições em que, perante o nosso direito, o julgamento criminal influi no juizo civil. Desde logo salienta que não se trata, no caso, de um problema de coisa julgada, mas sim, da influência recíproca de jurisdições. Registra a unânime opinião dos juristas de que tal influência sòmente se opera naquilo que é comum às duas jurisdições, de modo que não produz efeitos na esfera civil a absolvição fundada em qualquer motivo peculiar à instância criminal. Também não impede a ação civil a decisão penal absolutória: 1) que considera o fato ou a autoria incertos ou não provados; 2) que declare não constituir o fato um crime, pela ausência dos elementos que integram e caracterizam a infração penal; 3 ) motivada pela ocorrência de prescrição; 4) quando baseada em justificativa ou dirimente. Merecem ser transcritas aqui, as conclusões a que chega Aguiar Dias, quanto à aplicação dos princípios enumerados, respeito à eficácia da sentença penal na esfera administrativa:

"Embora não tenha a mesma categoria, a instância administrativa está, em relação às demais, na situação de liberdade, que, no decorrer dêste trabalho, temos procurado situar nos limites da competência exclusiva, aceitação dos fatos ou circunstâncias apurados na outra jurisdição, mas com autonomia para emprestar-Ihés sua própria apreciação. Esta só não é livre quando, por se conter na apre. ciação anterior, dela não possa discrepar, sob pena de contradição. Assim, não pode a instância administrativa aplicar sanção a quem foi declarado estranho ao fato ou, de qualquer forma, dar como existente fato negado em outra jurisdição. Mas pode, em face da isenção por motivo não comum às duas instâncias, aplicar suas próprias sanções. O fato, por exemplo, que não chegue a constituir crime, pode, não obstante a absolvição na instância criminal, dar lugar a demissão na instância administrativa e, com maior razão, a aplicação de penalidades menores, desde que umas e outras não estão condicionadas aos exatos pressupostos da sanção penal, precisamenie como a

18. Francisco Campos - Direito Administrativo (Pareceres), pg. 368 
ação civil pode ser julgada procedente, não obstante a improcedência da ação penal" (19).

11. Cabe ainda outra referência às lições de Aguiar Dias, apoiadas em Pierre Hébraud e no sentido de que sòmente quando a verificação jurisdicional de matéria de fato envolve a decisão de jurisdição posterior é que suprime, quanto a esta, a liberdade de reapreciá-la. Aí é que reside o ponto central da questão ora sob exame. É de se ver que, enquanto a prática do delito penal constitue o suporte necessário da ação civil, nos casos restritamente considerados, a verdade é que jamais tal condicionamente deve prevalecer com relação à aplicação de sanções disciplinares. É certo que, pelo direito positivo se vinculou, em determinadas situações, a punição do funcionário à constatação de que seu comportamento violou normas de direito penal; desde que sòmente será possível a penalização disciplinar se verificado um crime contra a administração pública, certamente não se poderá deixar de identificar, aí, um nítido traço de subordinação da instância administrativa ao pronunciamento, prévio ou posterior, da justiça penal. Especialistas nacionais vêm então criticar a terminolo. gia do atual Estatuto para considerá-la carente de técnica, uma vez que, na enunciação de outras faltas disciplinares dever-se-ia simplesmente adotar as nomenclaturas e os conceitos do Código Penal, porque também constituiriam crimes! (20). O que se pretende, portanto, é subjugar definitiva e inteiramente a Administração Pública à justiça criminal. O Direito disciplinar não passaria, então, de um ramo subalterno do Direito penal, com a função limitada de selecionamento dos crimes que devessem constituir causa de aplicação de faltas ao serviço.

12. Com referência às disposições art. 207 do Estatuto dos Funcionários Públicos Civís da União, têm-se porém melhor €sclarecido que o seu item I, "não definiu os atos infringentes da lei penal e, porisso, só à esfera judiciária competente é que cabe definir o delito, já que a administração não se acha autorizada a dizer que o funcionário cometeu crime". Já quanto às demais infrações disciplinares alí previstas, embora possam constituir crimes, não está na dependência do julgamento jurisdicional a aplicação das penas administrativas, uma vez que "elas não são punidaș pela administração em atenção ao fato de constituirem crime, mas por estarem definidas autônoma. mente pelo Estatuto, como seja, a lesão aos cofres públicos, a delapidação do patrimônio nacional, abandono de cargo, ofensa física em serviço e outras, que, porventura, possam, também, estar definidas no Código Penal como crimes" (21).

13. Max Querrien, em pronunciamento ainda mais favorável à

19. Aguiar Dias - Da Responsabilidade Civil, 3a. ed., vol. II, pgs. 815 e segts.

20. Temistocles Brandão Cavalcanti - O Funcionário Público e o seu Regime Jurídico, vol. $\mathrm{II}_{\text {; }}$ pg. 257. 21. Anibal de Mello Couto - Da responsabilidade do Servidor Público - Rev. Dir. Adm., vol.
37 , pg. 515. 
autonomia dos regimes disciplinares, acentuando que as faltas que os integram são definidas em relação às exigências do serviço público, cujas fronteiras são imprecisas e que inclusive abrangem certos aspectos da vida particular, política ou social do funcionário; daí porque não se poderá subordinar o exercício do poder disciplinar às decisões de autoridades judiciárias, "mesmo se uma instância estiver empenhada, em virtude dos mesmos fatos, perante tribunais repressivos". E ao finalizar suas considerações declara o ilustre Auditor do ConseIho de Estado francês que "nada há que se oponha a que duas modalidades de sanções, que não são inspiradas pelas mesmas considerações, venham atingir cumulativamente o funcionário culpado" (22).

14. Vale aquí repetir que, realmente, o Direito penal e o disciplinar são coisas inteiramente diversas, dominadas por princípios e técnicas diferentes, quer por seus fundamentos, quer pelos seus objetivos e finalidades, quer pela natureza própria de cada uma dessas disciplinas; é a técnica específica do Direito administrativo que deve empolgar os regimes disciplinares. Segundo as lições de Bielsa, Giese, Cino Vitta, Carlos Medeiros e Silva e outros eminentes juristas, basta qualquer transgressão aos deveres inerentes às relações de emprêgo, para que se justifique a sanção disciplinar. Nesse campo do Direito, as infrações não obedecem a enumeração taxativa, limitando-se os textos legais e regulamentares a enunciá-las de forma ampla, para que possam abranger tôdas as prováveis lesões ao bom funcionamento dos serviços. Admite-se mesmo a retroatividade da sanção nova, ou seja, a punição post facto, o que seria inconcebível no Direito penal comum (23). Enfim: a transgressão disciplinar consiste, substancialmente, na violação dos deveres funcionais que têm um conteúdo prevalentemente ético e não está inscrito, por inteiro, "nas taxativas fórmulas de direito" (24).

15. Mesmo sem desprezar o princípio da prévia definição das infrações disciplinares e suas sanções, é evidente que não pode a Administração ficar privada da sua autonomia quanto à estipulação dos fatos que, por atentarem contra a moralidade, organização e funcionamento dos serviços, ou a disciplina hierárquica, devam ficar sujeitos a medidas punitivas, independentemente da eventual caracterização desses mesmos fatos como delitos penais. Sendo o crime a mais grave infração do ordenamento jurídico, a êle corresponde pena de graduação superior, cuja imposição, ou não, jamais poderia prejudicar a aplicação de sanção disciplinar. O que se tem dito, aliás, é que sempre há, no delito penal, substância residual suficiente para justificar a punição disciplinar. Assim, quando se nega à Administração Pública a possibilidade de punir, autônomamente, um funcionário que praticou um ato eventualmente criminoso, por julgá-la carente dos 22. Max Querrien - A elaboração do Estatuto da Função Pública em França - Rev. Dir. Adm.,
vol. 36, pgs. 47 e segts.

23. Amilcar de Araujo Falcão - op. loc. cit.

24. Guido Zanobini - Corso di Diritto Amministrativo, vol. $111 / 240$. 
requisitos técnicos exigíveis para categorizá-la como poder jurisdicional, se esquece que, essa mesma Administração não está disputando qualquer prerrogativa própria dos órgãos judiciários, mas apenas atuando com a pretensão de exercer uma atribuição que legítimamente the pertence, qual seja, a de defender, pela sanção, a boa ordem e a disciplina dos serviços. Ou em outros têrmos: a Administração não apura a responsabilidade penal, mas apenas a responsabilidade disciplinar, para verificar se o funcionário procedeu, ou não, com improbidade. A declaração da inexistência de fato, pela justiça penal, não pode senão significar que tal fato não foi reconhecido como crime.

16. A supremacia do órgão jurisdicional penal poderá resultar, em determinados casos, na paralização da ação administrativa, em prejuizo da sua eficácia e oportunidade. Poderá também a decisão penal, é certo, determinar a reparação do injusto administrativo; tais efeitos porém, a par de estranhos às funções precípuas do órgão de repressão criminal, sòmente favoreceriam o funcionário que houvesse praticado qualquer ato com indícios caracterizadores do delito penal e não aquêle oụtro, acusado de infração menos grave, embora estivessem, ambos, sujeitos à mesma punição disciplinar. O que importa acentuar é que a garantia comum de todos quantos mantenham relações com a Administração Pública está no contrôle jurisdicional realizável por outras vias de direito que não seịa a da ação penal. Êsse contrôle atinge os atos administrativos, vinculados ou discricionários, e não se circunscreve aos aspectos externos da sua legalidade, mas considera a sua motivação e penetra no exame da matéria de fato, "para analisar os elementos de legalidade interna da conduta do administrador" (25).

17. E' de se considerar, por outro lado, que o processo de inquérito administrativo, já está atualmente regulado de forma satisfa. tòriamente a assegurar a ampla defesa do acusado e o respeito aos seus direitos subjetivos individuais. A crescente jurisdicionalização de certos órgãos da Administração Pública é, aliás, uma necessidade determinada pelo progresso e o surto da justiça administrativa é, em par ticular, "um dos traços característicos da vida pública moderna, pois obedece aos imperativos das realidades econômicas e sociais dos dias de hoje" (26). O crescente processo de jurisdicionalização do Estado e que se traduz, no dizer de Castro Nunes, "na sujeição dos seus atos à observância da norma geral, lei ou regulamento" (27), pode e deve alcançar a instância adminisłrativa, mediante sua adequada definição pelo direito positivo.

Quando se reclama, com insistência, a completa reforma da nossa legislação é, para atualizá-la "com a evolução havida desde a In-

25. Caio Tácito - O Abuso do Poder Administrativo no Brasil - Dasp, pg. 30.

26. Francisco Sá Filho - Relações entre os Poderes do Estado, pg. 247.

27. Castro Nunes - Teoria e Prática do Poder Judiciário, pg. 3. 
dependência na vida cultural do país", de forma a que o processo administrativo fique em condições de merecer a confiança do público em geral e, afinal, se constitua em um instrumento à altura do progresso jurídico (28).

28. Ruy Cirne de Lima, op. cit., pg. 210/11. 